\title{
Health consequences of violence within marriage: Need for strengthening the health sector response
}

Shireen J. Jejeebhoy

Population Council

K.G. Santhya

Population Council

Rajib Acharya

Population Council

Follow this and additional works at: https://knowledgecommons.popcouncil.org/departments_sbsr-pgy

Part of the Demography, Population, and Ecology Commons, Domestic and Intimate Partner Violence Commons, Family, Life Course, and Society Commons, International Public Health Commons, and the Women's Health Commons

How does access to this work benefit you? Let us know!

\section{Recommended Citation}

Jejeebhoy, Shireen J., K.G. Santhya, and Rajib Acharya. 2010. "Health consequences of violence within marriage: Need for strengthening the health sector response," Policy Brief no. 2. New Delhi: Population Council and UNFPA. 


\section{RESEARCH that makes a difference...}

\section{Health consequences of violence within marriage: Need for strengthening the health sector response}

Marital violence in India is a serious issue and an accepted practice. The most recent estimates show that as many as 35 percent of married women aged 15-49 had experienced physical violence and 10 percent had experienced sexual violence perpetrated by their current or former husband over the course of their married life (IIPS and Macro International, 2007). Policies and programmes have increasingly focused on preventing violence against women and supporting women who experience such violence. For example, the Protection of Women from Domestic Violence Act 2005, passed in 2006, adopts a broad definition of domestic violence, and provides for immediate and long-term relief to women in situations of violence of any kind in the home.

While the prevalence of violence within marriage is well documented in India, evidence of the adverse consequences of marital violence for women's health and well-being remains sparse and scattered. As a result, services that address the needs of women who have experienced marital violence are limited.
This policy brief provides a synthesis of available evidence of the magnitude of marital violence experienced by women, including married young women, in India, and the ways in which the experience of physical and sexual violence within marriage compromises health, with a focus on sexual, reproductive and child health, as well as mental health. It argues for strengthening the health sector response to address the needs of women who have experienced marital violence.

Evidence comes from an extensive review of over 25 published and unpublished studies on violence within marriage in India. This evidence is supplemented by further analyses of data from 3 major survey exercises on the situation of youth in India that enable us to link the experience of physical and sexual violence in marriage with a range of health outcomes.

Violence within marriage is common, including among the young Evidence indicates that between one-tenth and half of women surveyed in various

Figure 1: Magnitude of lifetime experience of physical and/or sexual violence within marriage among women aged 15-50

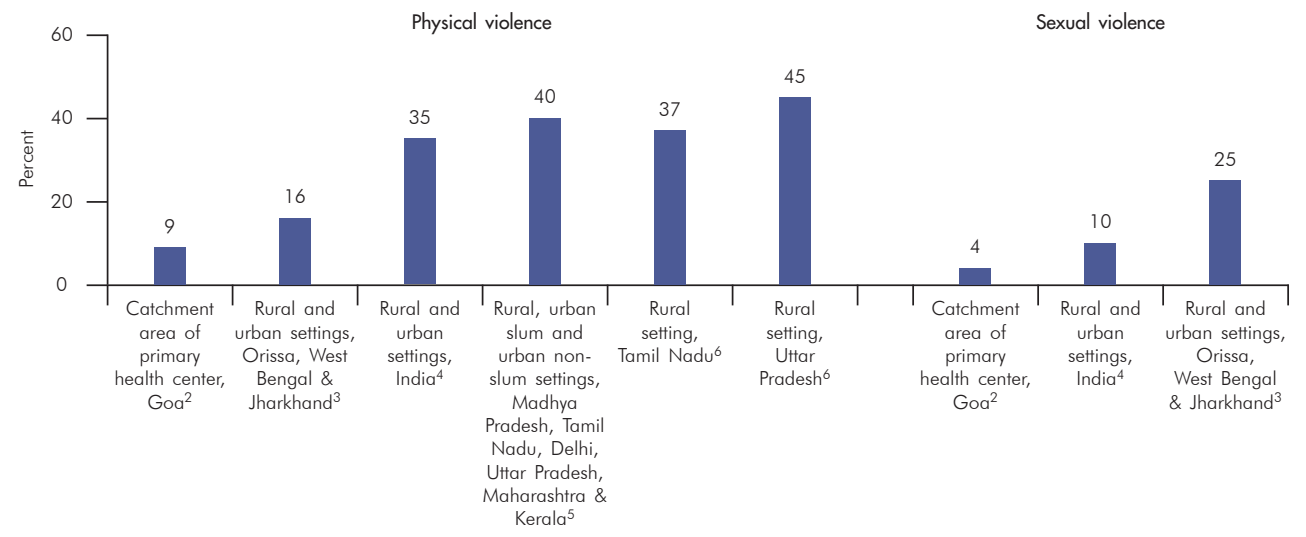


studies had experienced physical violence, and between one in twenty and one in four women had experienced sexual violence perpetrated by their husband. ${ }^{1}$

Sizeable proportions had experienced physical and/ or sexual violence even when they were pregnant-between one in 20 and half in the case of physical violence and between one in twenty and one in three in the case of sexual violence. ${ }^{1}$

Among young women, studies have shown that $21-56 \%$ had experienced physical violence and $11-56 \%$ had experienced sexual violence within marriage. ${ }^{1}$ Indeed, the experience of marital violence begins early in married life. Findings from one study show that $10 \%$ of young women had experienced physical violence and $27 \%$ had experienced forced sex from early on in married life. ${ }^{14}$

Health consequences of marital violence Adverse consequences of marital violence have been reported in a number of studies. They highlight, moreover, that many of these associations are observed early in marriage, suggesting that women are at risk of ill-health for much of their married life. Many studies have shown strong associations between women's experience of marital violence and adverse health outcomes, even after controlling for a range of socio-demographic background variables.

Figure 2: Magnitude of physical and/or sexual violence during pregnancy

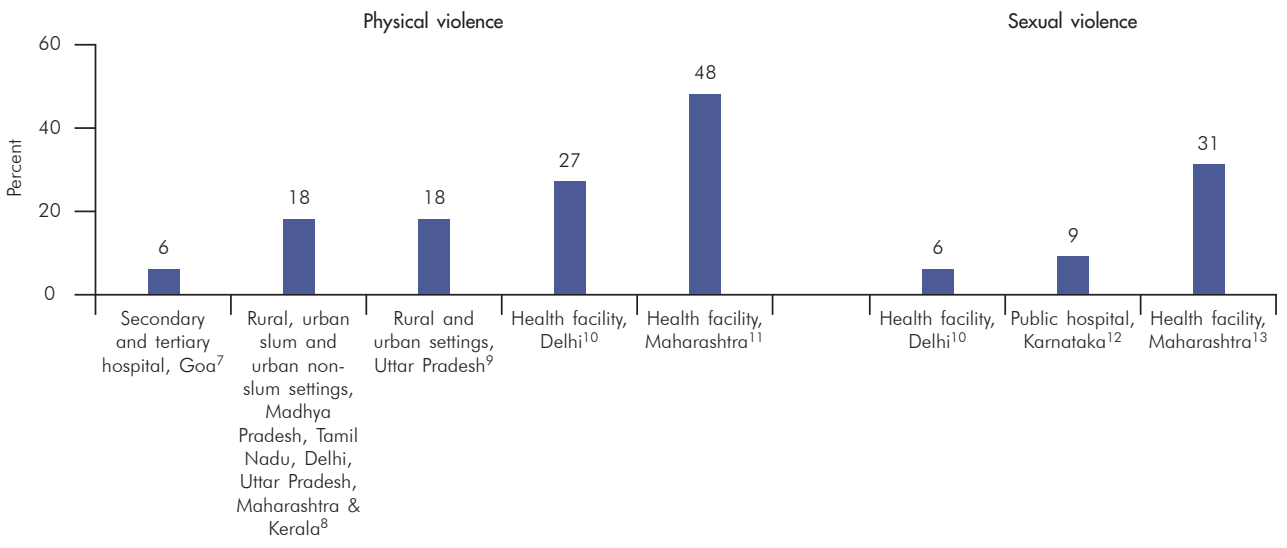

Figure 3: Magnitude of lifetime experience of physical and/or sexual violence within marriage among young women aged 15-24

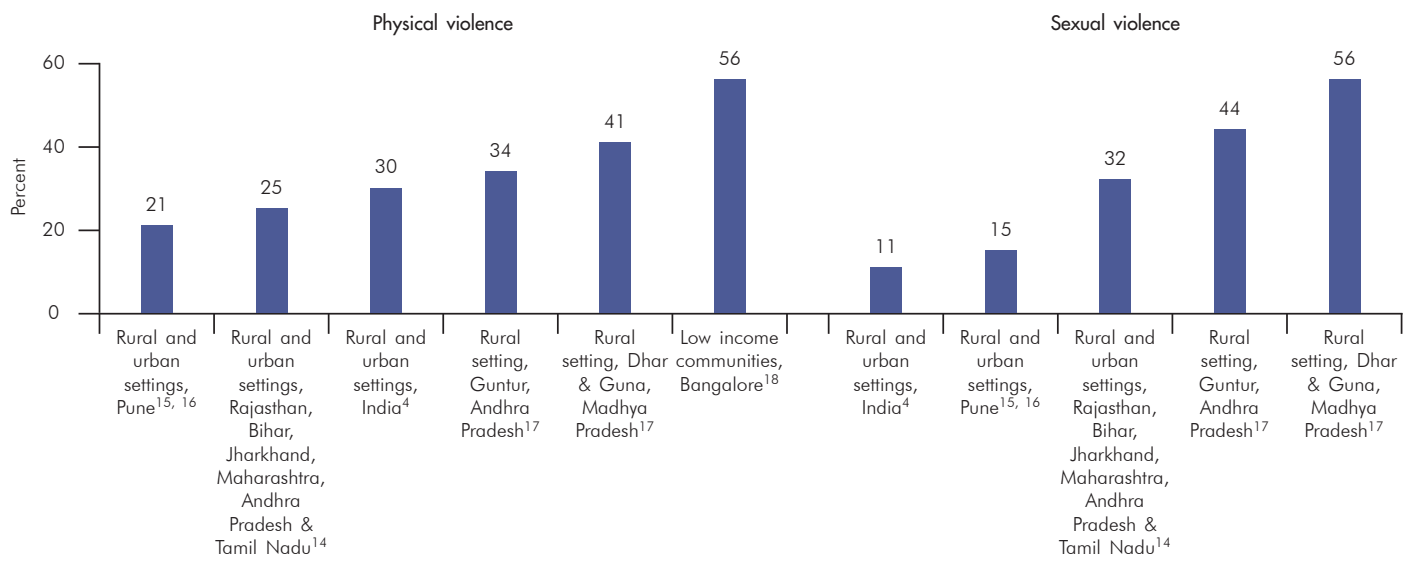


Figure 4: Association between marital violence and experience of symptoms of RTI/STI

$$
\text { Physical violence }
$$

Sexual violence

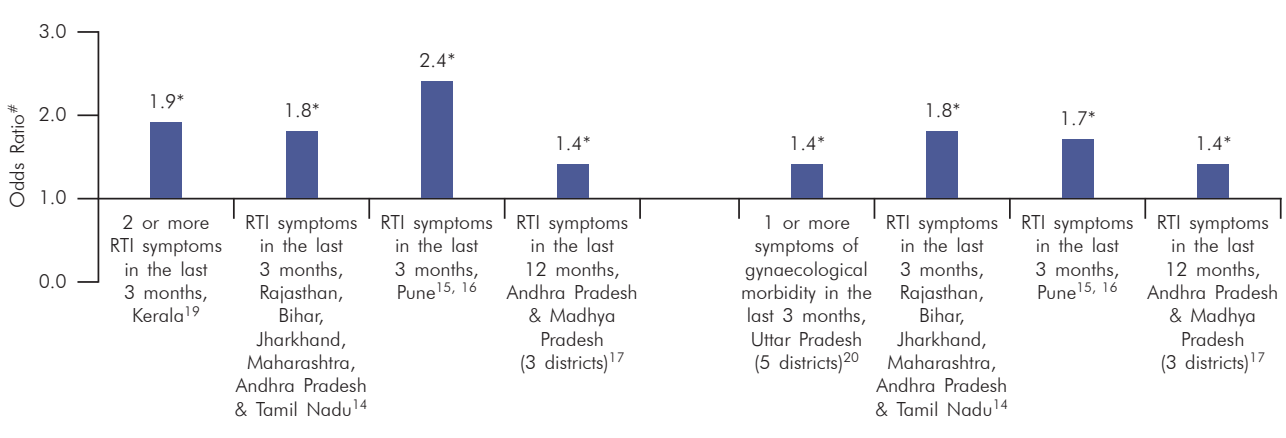

\#Odds ratios greater than 1 suggest the extent to which women who experience marital violence are more likely than those who have not to also experience a particular outcome after controlling for socio-demographic factors; conversely, odds ratios less than 1 suggest the extent to which they experience a particular outcome after controlling for
are less likely to experience a particular outcome.

*Statistically significant at .05 level or better, after controlling for the effects of a range of socio-demographic factors.

Marital violence is positively associated with reproductive tract infections (RTI)/ sexually transmitted infections (STI) and other gynaecological morbidity

A number of studies show that women who had experienced physical violence in marriage were up to two and a half times more likely, and those who had experienced sexual violence up to $80 \%$ more likely than those who had not experienced violence to report symptoms of infection (See Figure 4).

Studies that explored the links between marital violence-physical and sexual-and clinically or laboratory detected RTI/STI and HIV have also shown a clear association (see Figure 5). For example, women who had experienced physical and sexual violence were $70 \%$ and $90 \%$ more likely, respectively, than those who had not experienced such violence, to be diagnosed with endogenous infections such as bacterial vaginosis. ${ }^{21}$ Another study showed that the experience of sexual violence within marriage resulted in a threefold increase in women's risk of acquiring STIs. ${ }^{22}$ And a third study showed that women who experienced both physical and sexual violence were almost 4 times more likely than those who did not experience any violence to be HIV infected. $^{23}$
Marital violence increases the risk of pregnancy-related complications and compromises care seeking

The experience of marital violence also has consequences for women's pregnancy related experiences. Studies have shown that women who experienced physical violence were less likely than those who did not to seek antenatal care or were more likely to delay seeking antenatal care. Evidence from young women in one study suggests that those who experienced physical or sexual violence were, respectively, $40 \%$ and $70 \%$ more likely

Figure 5: Association between marital violence and experience of clinically/ laboratory detected RTI/STI

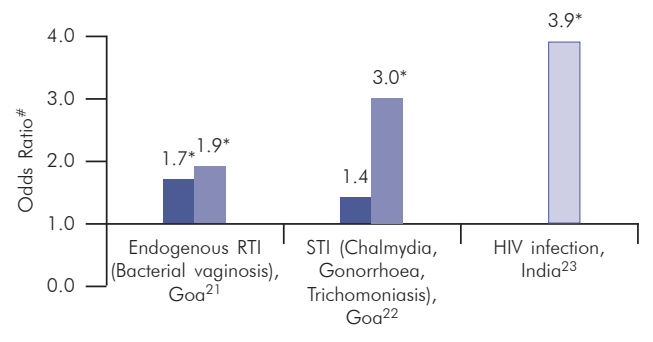

Physical violence Sexual violence $\square$ Physical \& sexual violence

\#Odds ratios greater than 1 suggest the extent to which women who experience marital violence are more likely than those who have not to also experience a particular outcome after controlling for
socio-demographic factors; conversely, odds ratios less than 1 suggest the extent to which they are less likely to experience a particular outcome. ${ }^{a}$

*Statistically significant at .05 level or better, after controlling for the effects of a range of socio-demographic factors.

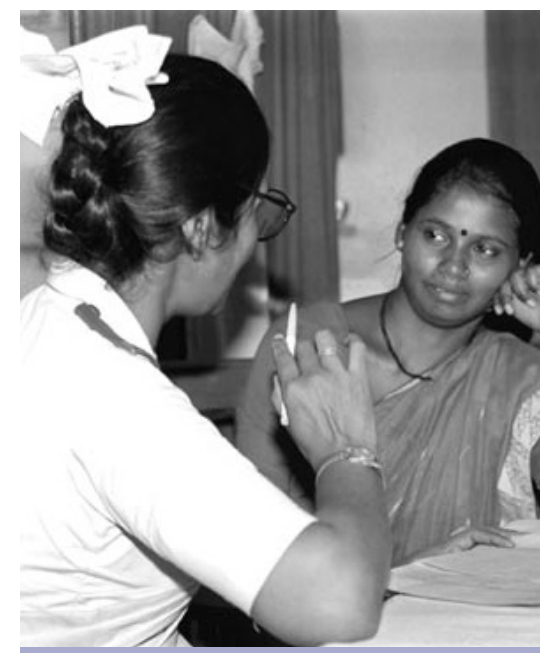


than those who did not experience violence to report pregnancy-related complications. ${ }^{17}$

Physical violence within marriage elevates chances of experiencing foetal, infant and early childhood mortality

Women who experienced physical violence in marriage were up to one-and-a-half times more likely than women who did not to have experienced foetal mortality, two to two-and-a-half times more likely to have experienced perinatal mortality, and one-and-a-half to two times more likely to have experienced neonatal mortality (See Figure 6). At the same time, while there are just a few studies, their findings show that both infant and early childhood mortality are significantly higher-10-20\% higheramong women who have experienced physical violence within marriage than among those who have not so experienced (See Figure 7). No such association was, however, observed with the experience of sexual violence.

Unwanted pregnancy and induced abortion are more likely to be reported by women who experience marital violence Unwanted pregnancy is also more likely among women-including the young - who experience marital violence than other women. While the strength of effects varied across studies, by and large, studies suggest that women who experienced physical and/ or sexual violence in marriage were $20-70 \%$ more likely than those who did not to report an unwanted pregnancy, although some studies have found that they were 2-3 times more likely to have so experienced (See Figure 8).

Information on the relationship between the experience of marital violence and induced abortion comes from studies of young

Figure 6: Association between physical violence within marriage and foetal, perinatal and neonatal mortality

Foetal mortality Perinatal mortality Neonatal mortality

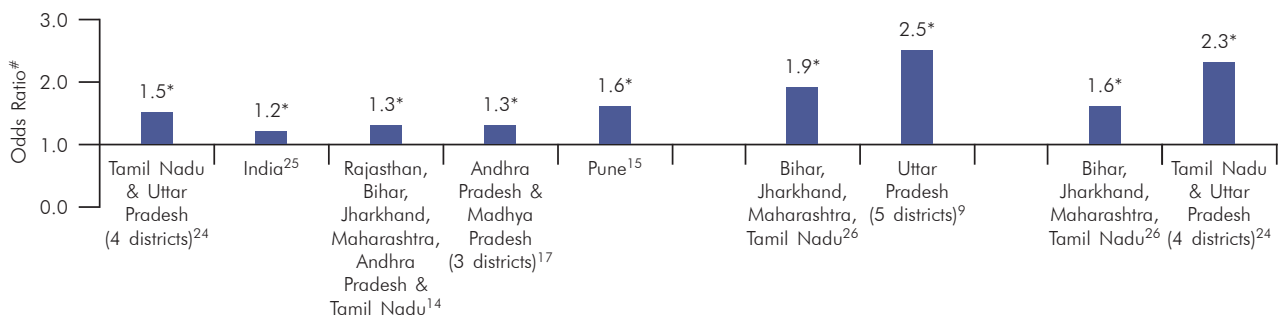

\#Odds ratios greater than 1 suggest the extent to which women who experience marital violence are more likely than those who have not to also experience a particular outcome after controlling for socio-demographic factors; conversely, odds ratios less than 1 suggest the extent to which they are less likely to experience a particular outcome.

*Statistically significant at .05 level or better, after controlling for the effects of a range of socio-demographic factors.

Figure 7: Association between physical violence within marriage and infant and early childhood mortality

Infant mortality

Childhood mortality

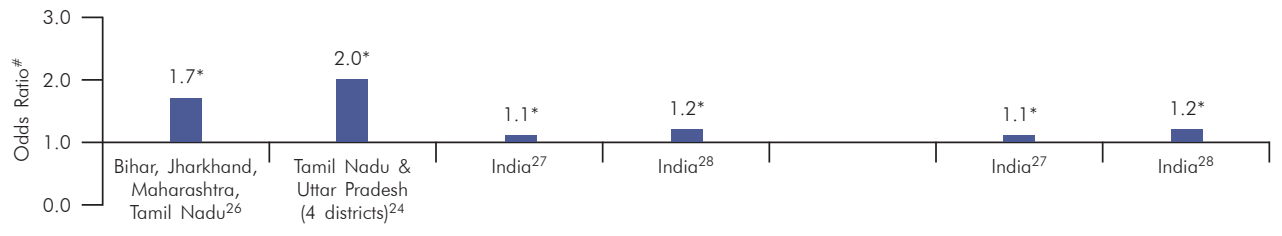

\#Odds ratios greater than 1 suggest the extent to which women who experience marital violence are more likely than those who have not to also experience a particular outcome after controlling for socio-demographic factors; conversely, odds ratios less than 1 suggest the extent to which they are less likely to experience a particular outcome. ${ }^{a}$

*Statistically significant at .05 level or better, after controlling for the effects of a range of socio-demographic factors. 
Figure 8: Association between marital violence and experience of unwanted pregnancy and abortion

Physical violence

Unwanted pregnancy

Induced abortion

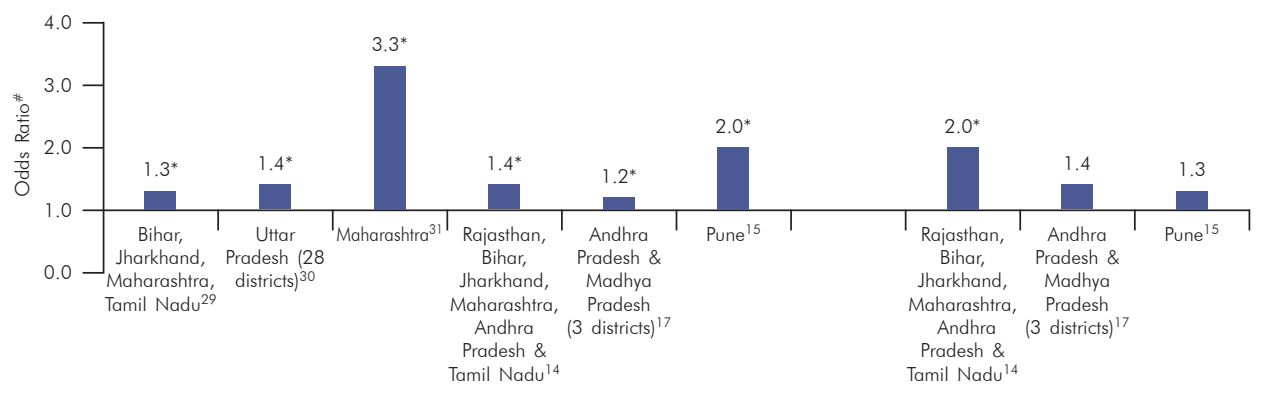

Sexual violence

Unwanted pregnancy

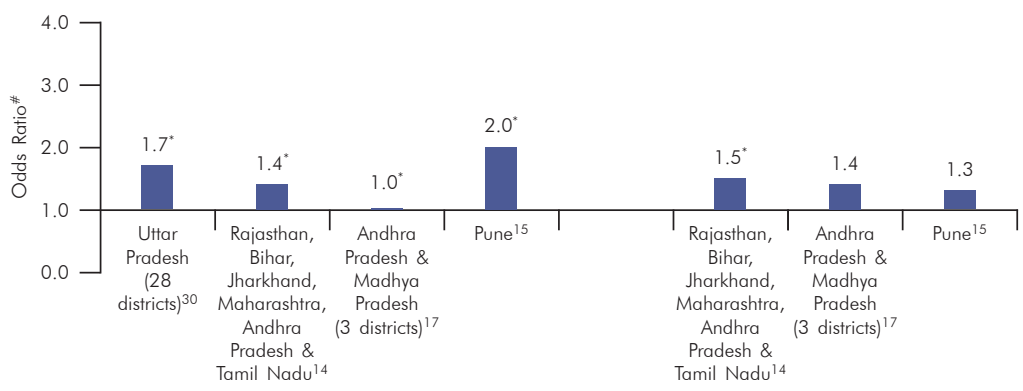

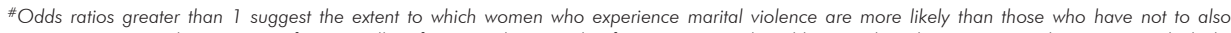
experience a particular outcome after controlling for socio-demographic factors; conversely, odds ratios less than 1 suggest the extent to which they are less likely to experience a particular outcome. ${ }^{\circ}$

*Statistically significant at .05 level or better, after controlling for the effects of a range of socio-demographic factors.

women. In one study of young women, those who experienced physical and sexual violence, respectively, were twice as likely as and $50 \%$ more likely than other women to have had an induced abortion. ${ }^{14}$

While evidence concerning the association with contraceptive practice was not as consistent, studies among married women of all ages do reiterate that marital violence compromised women's access to contraception.

\section{Marital violence affects the nutritional} status of women and children A study using NFHS-3 data showed that compared to women who did not experience violence, those who experienced physical violence were $27 \%$ more likely to be severely anaemic. Moreover, their children were $18 \%$ more likely to experience wasting, $14 \%$ more likely to be stunted and $34 \%$ more likely to be severely underweight. $^{32}$

Women who experience marital violence tend to report poor mental health status Findings also suggest that the experience of physical and sexual violence is positively correlated with the experience of symptoms or behaviours suggestive of mental health disorders. For example, studies find that, compared to women who did not experience physical violence in marriage, those who have done so are twice as likely to display symptoms of anxiety, and almost three times as likely to display postnatal depression. Symptoms of common mental disorders were 3.5 and 4.4 times more likely to be reported by those who

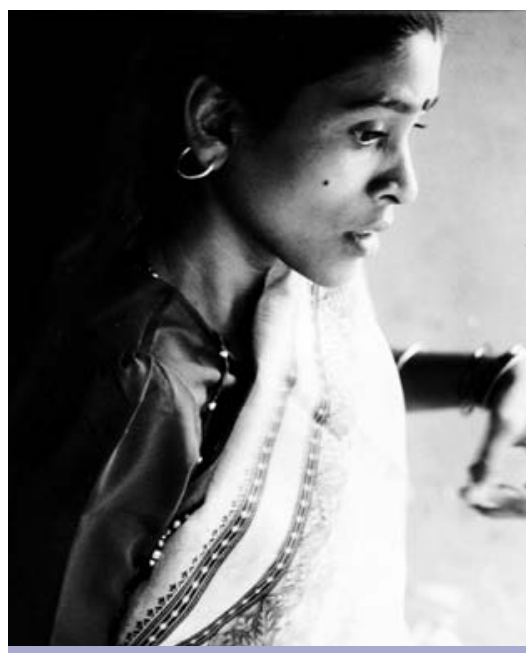


Figure 9: Association between marital violence and mental health outcomes

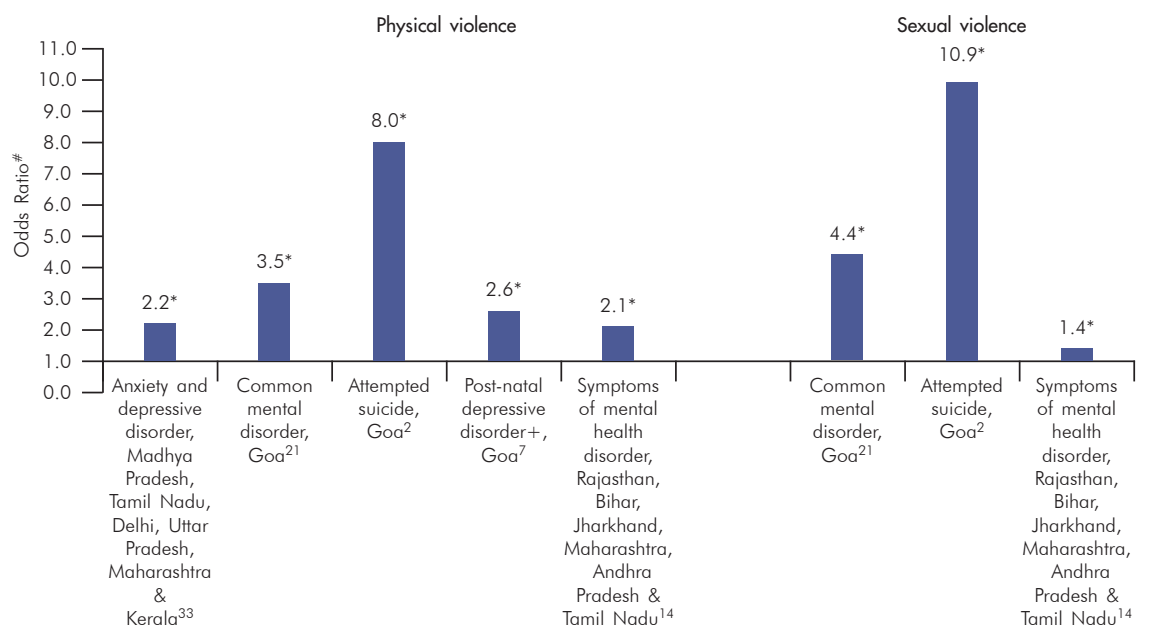

\#Odds ratios greater than 1 suggest the extent to which women who experience marital violence are more likely than those who have not to also experience a particular outcome after controlling for socio-demographic factors; conversely, odds ratios less than 1 suggest the extent to which they are less likely to experience a particular outcome.

*Statistically significant at .05 level or better, after controlling for the effects of a range of socio-demographic factors.

+Physical or sexual violence.

experienced physical and sexual violence, respectively, than those who had not done so. Even among young women, those who experienced physical violence were twice as likely as, and those who experienced sexual violence $40 \%$ more likely than those who had not to report 3 or more symptoms suggestive of mental health disorders (See Figure 9).

Attempted suicide was, in addition, considerably more likely to be reported by those who had experienced marital violence than other women: Indeed, one study found that women who experienced physical violence were 8 times more likely and those who had experienced sexual violence 11 times more likely, to have attempted suicide than other women. ${ }^{2}$

Why are we seeing these relationships? A number of explanations, biological and socio-cultural, may be offered for the consistent link observed between marital violence and indicators of ill-health:

- Trauma caused physical and sexual violence may result in gynaecologic morbidity.

- Sexual violence may cause vaginal or urethral trauma that may exacerbate women's risk of acquiring an infection.

- Marital violence in pregnancy may lead to foetal injury, pre-term delivery or stillbirth and provoke serious uterine bleeding.

- The experience of violence fosters a loss of self-esteem and feelings of helplessness and isolation that may result in poor mental health outcomes.

- Abused women are less likely than others to be able to communicate or negotiate with the husband on contraception and condom use and therefore more likely to face unmet need for contraception.

- They may lack the decision-making power, control over resources or the social support necessary to adopt protective actions for themselves and their children, resulting in, for example, limited contraception, difficulty in accessing timely pregnancy-related services or ensuring prompt newborn and child health services, and inability to ensure adequate nutrition for themselves and their children.

- Poor mental health outcomes may also affect women's ability to care for themselves and their children.

- Compromised ability to care for themselves and their children may result in low birth weight and pre-term 
delivery, which are well-known risk factors for perinatal and infant mortality.

- Men who perpetrate violence on their wife may also have other characteristics-risky extra-marital sex, non-use of condoms, experience of symptoms of infection-that place their wife at risk of infection.

\section{Programme recommendations}

Findings underscore the urgent need to strengthen efforts to prevent the incidence of marital violence. At the same time, given the widespread prevalence of marital violence, there is an urgent need, in the shorter term, to strengthen the health sector's response to marital violence.

\section{Screen and refer women who experience marital violence}

Women who experience marital violence may not always disclose the experience when they seek health care services. A top priority is therefore to screen and identify women who experience marital violence. Service protocols must be prepared that include violence screening while recording the regular history of women seeking health care services. Women who have experienced marital violence and attend a particular service may have health and other needs as well that the first point of contact is not equipped to address. It is important, therefore, that screening activities are linked with appropriate referral chains, including to services outside the health arena, for example, legal support, shelter and so on. Given that many abused women may not follow-up on referrals recommended by their primary provider, sensitive outreach activities must be included that support women to access these services.

\section{Screening activities must be provided in a} wide range of services

Women in need of care for adverse health consequences of marital violence may seek a number of services and it would be appropriate to establish screening mechanisms in all such services. For example, the immediate physical consequences of marital violenceabdominal/thoracic injuries, lacerations, fractures and burns-call for screening activities in emergency (casualty) services in general, as well as burns and orthopaedicrelated centres.

As most women visit a health centre at some point in their life for reproductive and child health services, these centres could serve as an important focal point to identify women who experience marital violence. Indeed, our findings call for the integration of violence screening in all sexual, reproductive and child health services, including safe motherhood and child survival programmes, VCTC and other HIV-related services. Moreover, findings highlighting the links between marital violence and adverse mental health outcomes emphasize that the National Mental Health Programme must incorporate a special focus on identifying and treating women who experience marital violence.

\section{Address provider level barriers}

Key provider level barriers include providers' lack of training on eliciting information and counselling women on genderbased violence, lack of time to provide related services, and providers' discomfort about communicating on the sensitive issue of marital violence with women. Training is needed to strengthen providers' skills in probing women's experiences sensitively, referring them appropriately and maintaining their confidentiality; at the same time, efforts must be made to change provider perceptions that marital violence is "normal" and a family affair, and that providers should not intervene in domestic matters. ASHAs and Integrated Child Development Services (ICDS) workers should be made aware of the links between marital violence and health and survival outcomes for women and children, and trained to support women experiencing marital violence. Finally, health care providers must be made aware of the laws surrounding violence against women and the sources of support available to women from sectors other than health (access to the police, the legal system, shelter, and NGOs, for example).

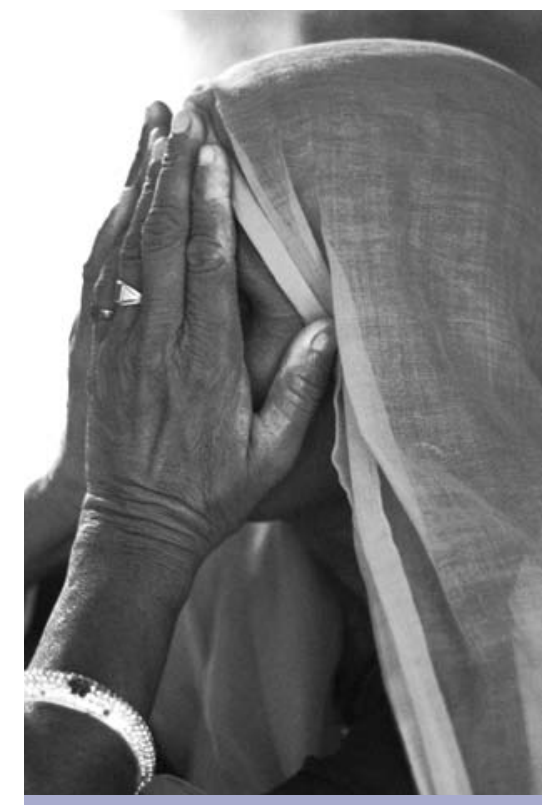




\section{References:}

1 Jejeebhoy, S., K. G. Santhya and R. Acharya. 2010. Health and social consequences of marital violence: A synthesis of evidence from India. New Delhi: Population Council and UNFPA.

2 Chowdhary, N. and V. Patel. 2008. "The effect of spousal violence on women's health: Findings from the Stree Arogya Shodh in Goa, India," Journal of Postgraduate Medicine, 54(4):306-312

3 Babu, V. B and S. K. Kar. 2009. "Domestic violence against women in eastern India: A population-based study on prevalence and related issues," BMC Public Health, 9:129.

4 International Institute for Population Sciences (IIPS) and Macro International. 2007. National Family Health Survey (NFHS-3), 2005-06: India, Volume 1. Mumbai: IIPS.

5 International Centre for Research on Women (ICRW). 2000. Domestic Violence in India: A Summary Report of a Multi-Site Household Survey (vol. 3). Washington, D.C.: ICRW.

6 Jejeebhoy, S.J. 1998. “Wife-beating in rural India: A husband's right?” Economic and Political Weekly, 33(15):855-862.

7 Patel, V., M. Rodrigues and N. DeSouza. 2002. “Gender, poverty, and postnatal depression: A study of mothers in Goa, India," American Journal of Psychiatry, 159:43-47.

8 Peedicayil, A., L. S. Sadowski, L. Jeyaseelan et al. 2004. "Spousal physical violence against women during pregnancy," International Journal of Obstetrics and Gynaecology, 111(7):682-687.

9 Ahmed, S., M. A. Koenig and R. Stephenson. 2006. "Effects of domestic violence on perinatal and early childhood mortality: Evidence from North India," American Journal of Public Health, 96(8):1423-1428.

10 Singh, P., R. Rohtagi, S. Soren, M. Shukla et al. 2008. "The prevalence of domestic violence in antenatal attendees in a Delhi hospital," Journal of Obstetrics and Gynaecology, 28(3):272-275.

11 Chhabra, S. 2007. "Physical violence during pregnancy," Journal of Obstetrics and Gynaecology, 27(5):460-463.

12 Varma, D., P. S. Chandra, T. Thomas et al. 2007. "Intimate partner violence and sexual coercion among pregnant women in India: Relationship with depression and post-traumatic stress disorder," Journal of Affective Disorders, 102(1):227-235.

13 Chhabra, S. 2008. "Sexual violence among pregnant women in India," Journal of Obstetrics and Gynaecology, 34(2):238-241.

14 International Institute for Population Sciences (IIPS) and Population Council. 2010. Youth in India: Situation and Needs 2006-2007. Mumbai: IIPS.

15 Alexander, M., L. Garda, S. Kanade et al. 2006. Formation of Partnerships among Young Women and Men in Pune District, India. New Delhi: Population Council.

16 Acharya, R. and S. J. Jejeebhoy. 2008. Adverse Health Outcomes of Physical and Sexual Violence within Marriage: Experiences of Young Women in Maharashtra, India. Paper presented at the Conference "Lessons learned and future challenges in the Reproductive Health Program," 28-29 February. New Delhi.

17 Santhya, K. G., S. J. Jejeebhoy and S. Ghosh. 2008. Early Marriage and Sexual and Reproductive Health Risks: Experiences of Young Women and Men in Andhra Pradesh and Madhya Pradesh, India. New Delhi: Population Council.

18 Rocca, C. H., S. Rathod, T. Falle et al. 2009. "Challenging assumptions about women's empowerment: Social and economic resources and domestic violence among young married women in urban south India," International Journal of Epidemiology, 38(2):577-585.

19 Sudha, S., S. Morrison and L. Zhu. 2007. "Violence against women, symptom reporting, and treatment for reproductive tract infections in Kerala state, southern India," Health Care Women International, 28:268-284.

20 Stephenson, R., M. A. Koenig and S. Ahmed. 2006. "Domestic violence and symptoms of gynaecological morbidity among women in north India," International Family Planning Perspectives, 32(4):201-208.

21 Patel, V., H.A. Weiss, D. Mabey et al. 2006. "The burden and determinants of reproductive tract infections in India: A population based study of women in Goa, India," Sexual Transmitted Infection, 82:243-249.

22 Weiss, H. A., V. Patel, B. West et al. 2008. "Spousal sexual violence and poverty are risk factors for sexually transmitted infections in women: A longitudinal study of women in Goa, India," Sexually Transmitted Infection, 84(2):133-139.

23 Silverman, J. G., M. R. Decker, N. Saggurti et al. 2008. "Intimate partner violence and HIV infection among married Indian women," Journal of the American Medical Association, 300(6):703-710.

24 Jejeebhoy, S.J. 1998. "Associations between wife-beating and foetal and infant death: Impressions from a survey in rural India," Studies in Family Planning, 29(3):300-308.

25 Johnson, N.E. and M. Sengupta. 2008. "Do battered mothers have more foetal and infant deaths? Evidence from India," Population Studies Center Research Report 08-634.

26 Koenig, M.A., R. Stephenson, R. Acharya et al. 2010. "Domestic violence and early childhood mortality in rural India: Evidence from prospective data," International Journal of Epidemiology, 39(3):825-833.

27 Singh, A., B. Mahapatra and S. Dutta. 2008. "Spousal abuse and infant and child mortality in India," Asia-Pacific Population Journal, 23(2):33-54.

28 Ackerson, L. K. and S. V. Subramanian. 2009. "Intimate partner violence and death among infants and children in India," Pediatrics, 124(5):e878-e889.

29 Stephenson, R., M. A. Koenig, R. Acharya et al. 2008. "Domestic violence, contraceptive use, and unwanted pregnancy in rural India," Studies in Family Planning, 39(3):177-186.

30 Martin, S., B. Kilgallen, A. O. Tsui et al. 1999. "Sexual behaviors and reproductive health outcomes: Associations with wife abuse in India," Journal of the American Medical Association, 282(20):1967-1972.

31 Purwar, M.B., L. Jeyaseelan, U. Varhadpande et al. 1999. "Survey of physical abuse during pregnancy in GMCH, Nagpur, India," Journal of Obstetrics and Gynaecology Research, 25(3):165-171.

32 Ackerson, L K. and S.V. Subramanian. 2008. "Domestic violence and chronic malnutrition among women and children in India," American Journal of Epidemiology, 167:1188-1196.

33 Kumar, S., L. Jeyaseelan, S. Suresh et al. 2005. "Domestic violence and its mental health correlates in Indian women," British Journal of Psychiatry, 187:62-67.

a For example, an odds ratio of 1.8 would suggest that women who have experienced violence are $80 \%$ more likely than other women to report a particular outcome; an odds ratio of 0.6 would suggest that they are, conversely, $40 \%$ less likely to experience a particular outcome.

Suggested citation: Jejeebhoy, S., K. G. Santhya and R. Acharya. 2010. Health consequences of violence within marriage: Need for strengthening the health sector response. Policy Brief No. 2. New Delhi: Population Council and UNFPA.

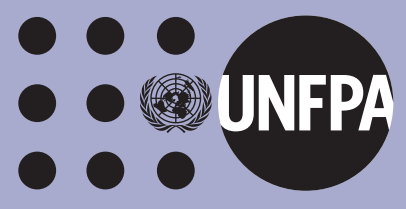

For further information please contact:

Population Council

South \& East Asia-Regional office

Zone 5-A Ground Floor

India Habitat Centre

Lodi Road

New Delhi 110 003, India

Tel: 91-11-2464 2901

E-mail: info-india@popcouncil.org

www.popcouncil.org

Donor

United Nations Population Fund (UNFPA)

The information and views expressed in this document do not necessarily reflect the views of the United Nations Population Fund or the United Nations. 